\title{
A FINANCIAL ANALYSIS OF RESWITCHING
}

\author{
RAFAEL GARCÍA IBORRA
}

Fecha de recepción: 26 de mayo de 2020

Fecha de aceptación: 11 de septiembre de 2020

\section{Introduction}

The classical Austrian Business Cycle Theory (ABCT) is based on an inverse relationship between the so-called Average Period of Production (APP) or 'roundaboutness' and the interest rate. According to Böhm-Bawerk (1884 [1891]), the APP is the weighted average time that a unit of labor is locked up in the production process $^{1}$; moreover, there is a positive relationship between savings (the 'subsistence fund') and the APP: the higher the latter the higher the former, which implies an inverse relationship between interest rates and the APP. Thus, a lower interest rate will lead to a higher APP ceteris paribus ${ }^{2}$.

\footnotetext{
1 Böhm Bawerk's APP $=\frac{\sum_{t=1}^{n}(n-t+1) l_{t}}{\sum_{t=1}^{n} l_{t}}$, where $l$ represent labor units, $n$ the number of time periods, and $t$ goes from 1 to $n$ and represents an index for each period (BöhmBawerk 1884 [1891], p. 89).

2 'Thus it is - and here we come to the last part of our threefold propositionthat, in reasonable economic speculation, the current productive powers will and must, on the average, be directed to remote productive purposes (or, in other words, invested in longer production periods), in proportion to the length of time for which the existing stock of wealth is able to provide. If the accumulated wealth is so small that it only provides subsistence for one year, it is perfectly clear that it is impossible to invest the current productive powers in processes that average three years, since, in the interval that must elapse between the consumption of the old wealth and the production of the new, the people would starve. And it is equally clear that it would be, in the highest degree, foolish and uneconomic to make the production period shorter than the existing wealth allows. The average period of production in a community is
} 
Hayek (2008) based his Hayekian triangles on Böhm-Bawerk's work: a lower (higher) interest rate leads to a more (less) roundabout structure of production, increasing (decreasing) the APP. Including Mises's (1921) business cycle theory into the analysis, whenever the interest rate is pushed lower than its 'natural level', either by the central bank or the banking system, there is an unsustainable extension of the APP that will generate an economic boom; the crisis will irremediably follow, as the APP will pull back towards its natural level.

From this brief characterization of the ABCT, it is easy to notice the key role of the inverse relationship between interest rates and roundaboutness; without it, there is no connection from changes in interest rates and roundaboutness, and the ABCT falls apart. The reswitching of techniques is precisely a counterexample to that relationship, as it claims there are situations in which lower interest rates do not lead to more roundabout productive structures.

The organization of this paper is as follows: the next section describes the reswitching of techniques as stated by Samuelson (1966) and the implication for the classical ABCT, based on a physical measure of roundaboutness; section 3 analyzes the alternative of applying corporate finance to the $\mathrm{ABCT}$ following Cachanosky and Lewin (2014). Section 4 is a financial analysis of Samuelson's example, argues why modified duration should replace BöhmBawerk's APP as a measure of roundaboutness, and shows why it does not represent a paradox to the ABCT when the financial approach is used. Sections 5 and 6 address the question from two additional perspectives: a neoclassical with fully flexible prices but fixed techniques and the Austrian related dynamic efficiency. Section 7 concludes.

in exact correspondence with the amount of its stock of wealth, and is entirely conditioned by it.' (Böhm-Bawerk 1884 [1891], p. 325). 


\section{Samuelson's reswitching of techniques}

Initially proposed by Sraffa (1960) in what came to be known as the 'Cambridge capital controversy'3, the phenomenon of reswitching was famously characterized by Samuelson, with a simple example, in his classic "A Summing Up" (Samuelson 1966). He compared two different techniques $A$ and $B$ for the production of champagne:

\section{TABLE 1. PRODUCTION TECHNIQUES A AND B}

\begin{tabular}{cccc}
\hline Technique & Labor Period $\mathbf{t}=\mathbf{3}$ & Labor Period $\mathbf{t}=\mathbf{2}$ & Labor Period $\mathbf{t}=\mathbf{1}$ \\
\hline $\boldsymbol{A}$ & 0 & 7 & 0 \\
\hline $\boldsymbol{B}$ & 6 & 0 & 2 \\
\hline
\end{tabular}

In order to deliver one unit of output in time $t, A$ employs 7 units of labor invested for 2 time periods; $B$ needs 2 units of labor for 3 time periods and 6 invested during only 1 period. Entrepreneurs will select the technique with the lowest capitalized labor cost (CLC), at the prevailing market interest rate, as per Table 2:

TABLE 2. CHOSEN TECHNIQUE FOR EACH CAPITALIZATION RATE

\begin{tabular}{cccc}
\hline Capitalization rate & CLC $\boldsymbol{A}$ & CLC $\boldsymbol{B}$ & Selected technique \\
\hline $125 \%$ & 35,44 & 36,28 & $A$ \\
\hline $100 \%$ & 28,00 & 28,00 & Indifferent \\
\hline $75 \%$ & 21,44 & 21,22 & $B$ \\
\hline $50 \%$ & 15,75 & 15,75 & Indifferent \\
\hline $25 \%$ & 10,94 & 11,41 & $A$ \\
\hline $0 \%$ & 7,00 & 8,00 & $A$ \\
\hline
\end{tabular}

${ }^{3}$ A full analysis of the implications of the controversy is out of the scope of this paper, especially whether capital can be considered as a factor of production. I will focus on the financial approach that considers as capital the value of any combination of capital goods. For a discussion of the Cambridge controversy see Cohen (2010). For a recent contribution from the Cambridge UK side on reswitching, see Fratini (2019a). 
Samuelson (1966, p. 570) notes that Böhm-Bawerk's APP is higher for $A$ (2, as the 7 labor units employed are invested for 2 periods) than for $B$ (1.5, as 6 units are employed during 1 period and the additional 2 units for 3 time periods). Therefore, and according to the $\mathrm{ABCT}$, for some particular interest rate $i^{*}$ which would work as a hurdle, $A$ should be preferred if the market interest rate is below $i^{*}$; conversely, $B$ will be chosen if it is above $i^{*}$.

We can see in Table 2 that, for an interest rate lower than $50 \%, A$ is chosen over $B$, which fits with the traditional ABCT; however, $A$ is preferred again whenever the interest rate is above $100 \%$, something that contradicts the inverse relationship between interest rates and APP: a serious blow to the ABCT.

We can plot the spread between the CLCs of technique $A$ minus those of $B$ for different capitalization rates:

FIG.1: PRODUCTION TECHNIQUE $A$ IS SELECTED FOR A

CAPITALIZATION RATE BELOW 50\% AND ABOVE 100\%, B IS PREFERRED FOR A CAPITALIZATION RATE BETWEEN 50 AND $100 \%$. THEREFORE THERE IS A SWITCH OF TECHNIQUES AT 50\% AND A RE-SWITCH AT 100\%

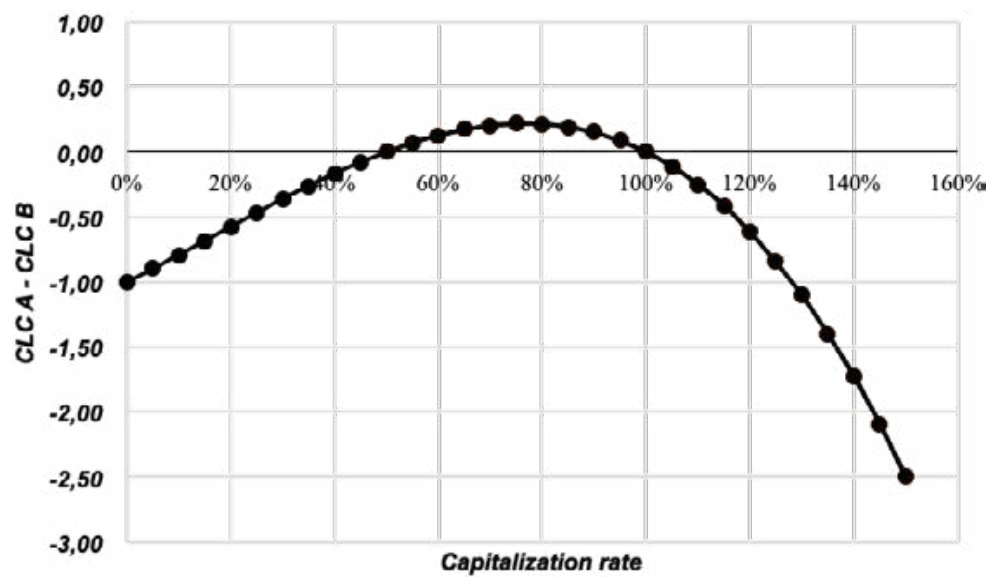

In Figure 1, a positive number in the vertical axis implies $B$ will be preferred ( $A^{\prime}$ s capitalized labor costs are higher than $B^{\prime}$ s); 
entrepreneurs will select technique $A$ whenever the interest rate is lower than $50 \%, B$ when it is between $50 \%$ and $100 \%$ and switch back to $A$ for levels above $100 \%$. There is no linear relationship between the interest rate and the chosen technique, as the economy exhibits two interest rate hurdles (50\% and 100\%), not one as assumed by the ABCT. More recently, Garrison (2005: 6-10) has proved that Samuelson's example is not an isolated case: reswitching examples can be easily generated with more realistic capitalization rates. In conclusion, if $A B C T$ is to be rescued, it will have to be severed from Böhm-Bawerk's APP.

\section{The Average Period of Production and Financial Duration}

Böhm-Bawerk's APP can be criticized due to (1) its reliance on physical units of labor, which requires homogeneous units in order for the APP to be computed, (2) its backward-looking approach, that conflicts with the forward-looking activity carried out by entrepreneurs and (3) the lack of a clear demarcation when deciding how many past labor inputs have to be included for those goods produced by a combination of labor and capital. In general, it can be said APP's weaknesses come from the attempt to use objective inputs, specifically homogeneous labor units, not labor values, something that contradicts the subjective approach of Austrian Economics (Huerta de Soto 2010, p. 32).

As noted by Cachanosky and Lewin (2014), Hicks (1953, p. 186) provided an alternative measure of the APP formulated on subjective factors:

$$
A P P=\frac{\sum_{t=0}^{n} \beta_{t} \cdot \chi_{t} \cdot t}{\sum_{t=1}^{n} \beta_{t} \cdot \chi_{t}}
$$

Where $\beta_{t}$ is the discount factor for period $t$ of the form $\beta_{t}=\frac{1}{\left(1+r_{t}\right)^{t}}$ with $r_{t}$ representing the interest or discount rate $^{4}, X_{t}$ is the

\footnotetext{
${ }^{4}$ Although different discount factors for each period can be used, the standard practice is to use a single one that provides the same result.
} 
monetary flow for period $t, n$ the number of time periods, and $t$ goes from 0 to $n$ and represents an index for each period. Therefore, Hicks's APP's has three main differences versus BöhmBawerk's: (1) it uses monetary values instead of labor units ${ }^{5}$, (2) cash flows are discounted, so that the time value of money is included and (3) it is forward-looking.

Hicks's APP is equivalent to the Macaulay duration (Macaulay 1938) commonly used in fixed income analysis and corporate finance ${ }^{6}$. Both measures represent: '[...] the average length of time for which the various payments are deferred from the present, when the times of deferment are weighted by the discounted value of the payments.' (Hicks 1953, p. 186, his emphasis).

Thus, different streams with the same present value for a specific discount rate, but with different duration, will have different behaviors for the same change in the interest rate:

"It follows at once form all this that if the average period of the stream of receipts is greater than the average period of the standard stream with which we are comparing it, a fall in the rate of interest will raise the capital value of the receipts stream more than that of the standard stream, and will therefore increase income." (Hicks 1953, p. 187).

From the Macaulay duration, it is possible to calculate the modified duration (MD):

$$
M D=\frac{D}{(1+I R R)}
$$

Where $D$ is the Macaulay duration and $I R R$ the internal rate of return of the stream of cash flows, i.e. the discount rate that makes the present value of the stream equal to $0^{7}$.

${ }^{5}$ We can also use the same notation as in Böhm-Bawerk's APP: $X_{t}=l_{t} \cdot W$, where $w$ is the nominal wage.

${ }^{6}$ For simplicity, I will use the two terms Macaulay duration and duration when referring to this measure.

7 It is customary to define modified duration as $M D=-\frac{D}{(1+I R R)}$ to reflect the reverse relationship between interest rates and the price of a fixed cash flow stream. However, I will omit the negative sign, in line with the standard usage in financial 
MD is the semi-elasticity of the present value with respect to a unit change in the discount rates; therefore, the relevant property of MD is that it is a measure of the sensitivity of the present value of the cash flow stream to changes in the discount rate; more specifically, it provides the percentual change of the present value with respect to a change of $100 \mathrm{bps}$ in the discount rate. The higher the modified duration of a cash flow stream, the higher the sensitivity of its present value to changes in the discount rate.

In conclusion, apart from the physical approach of BöhmBawerk, there is an alternative interpretation of roundaboutness that better reflects the Austrian approach: the one based on corporate finance. Instead of trying to capture the time on average a unit of labor is 'locked up' in the production process, the focus is shifted towards the sensitivity of the productive structure to changes in interest rates.

Cachanosky and Lewin (2014) have argued that Hick's APP/ Macaulay duration and modified duration are more appropriate measures to be used by the Austrian capital theory but, I will argue, only the latter suits for that role, and can also be applied to the reswitching of techniques.

\section{The Samuelson example and the financial approach}

In this section, I will analyze the Samuelson's example following the financial approach. The first step is to adapt the formulas of duration and modified duration: the simple case examined is based on the labor theory of value in which labor costs have to be capitalized, instead of the standard financial case of future cash flows being discounted to present values. In other words, we need to transform Hicks' forward-looking APP into a backward-looking APP8:

markets, to focus on the sensitivity of the cash flow stream to changes in interest rates. In any case, this choice will not affect the argument.

8 Lewin and Cachanosky (2019) have argued that their interpretation of duration as roundaboutness only applies to a forward-looking approach. However, from a financial perspective it can also be applied to backward-looking streams. 


$$
\text { Hicks'backward - looking } A P P=\frac{\sum_{t=0}^{n} \beta_{t} \cdot \chi_{t} \cdot t}{\sum_{t=1}^{n} \beta_{t} \cdot \chi_{t}}
$$

Where the only difference is the discount factor which now is of the form: $\beta_{t}=\left(1+r_{t}\right)^{n-t+1}$. The formula for the modified duration remains the same.

Calculating Hicks's backward-looking APP/Macaulay duration for both techniques and for each capitalization rate:

TABLE 3. HICKS'S APP/MACAULAY DURATION FOR PRODUCTION TECHNIQUES $A$ AND $B$

\begin{tabular}{ccc}
\hline Capitalization rate & Hicks's APP of $\boldsymbol{A}$ & Hicks's APP of $\boldsymbol{B}$ \\
\hline $150 \%$ & 2,00 & 2,35 \\
\hline $125 \%$ & 2,00 & 2,26 \\
\hline $100 \%$ & 2,00 & 2,14 \\
\hline $75 \%$ & 2,00 & 2,01 \\
\hline $50 \%$ & 2,00 & 1,86 \\
\hline $25 \%$ & 2,00 & 1,68 \\
\hline $0 \%$ & 2,00 & 1,50 \\
\hline
\end{tabular}


FIG. 2 A'S MACAULAY DURATION OR HICKS'S APP IS CONSTANT AT 2 WHILE B'S INCREASES WITH THE CAPITALIZATION RATE

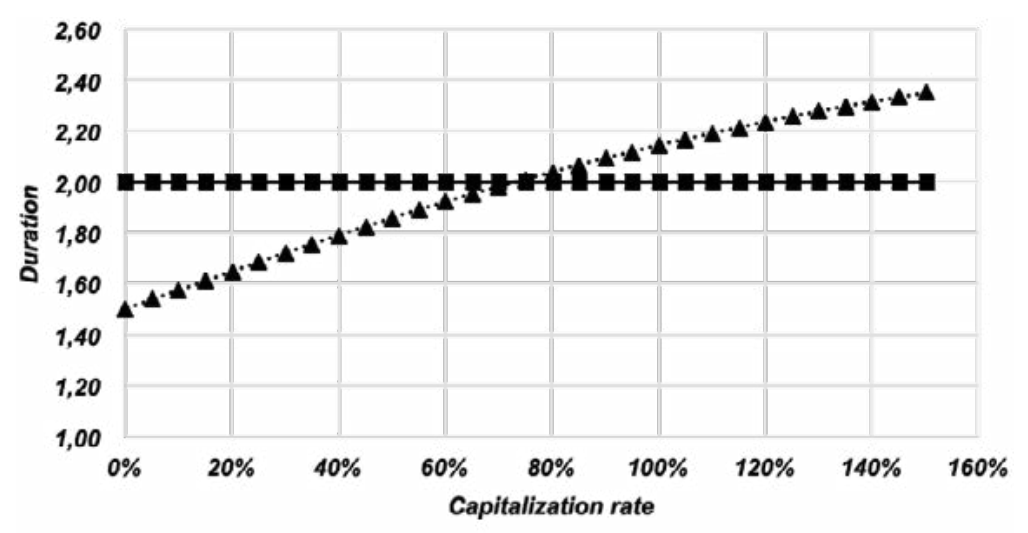

$\longrightarrow$ Duration A $\quad \cdots \cdot \cdots$ Duration B

The Macaulay duration is 2 for $A$, regardless of the capitalization rate, as it only has one cash flow in period $t-2$, just like a zero coupon bond with a maturity of two years. For $B$, there is a positive relationship between duration and interest rate: Hick's APP increases as the capitalization rate goes up, as the 'value weight' of the 2 labor units employed in $t=1$ increases $^{9}$. This result may sound counter-intuitive: in standard fixed income analysis, Macaulay duration decreases as the internal rate of return of a bond increases. This discrepancy is due to the reason stated above: in this example, the cash flows have to be capitalized instead of being discounted.

The next step is obtaining the modified duration for both $A$ and $B:$

${ }^{9}$ For the same cash flow stream and a capitalization rate of $0 \%$, Böhm-Bawerk's APP and Hicks' are equal; therefore, the former can be interpreted as a particular case of the latter, when the discount rate is $0 \%$, and assuming we do not use labor units but the value of labor units. 
TABLE 4. MODIFIED DURATION FOR EACH PRODUCTION TECHNIQUE AND CAPITALIZATION RATE

\begin{tabular}{ccc}
\hline Capitalization rate & Modified Duration $\boldsymbol{A}$ & Modified Duration $\boldsymbol{B}$ \\
\hline $150 \%$ & 0,80 & 0,94 \\
\hline $125 \%$ & 0,89 & 1,00 \\
\hline $100 \%$ & 1,00 & 1,07 \\
\hline $75 \%$ & 1,14 & 1,15 \\
\hline $50 \%$ & 1,33 & 1,24 \\
\hline $25 \%$ & 1,60 & 1,35 \\
\hline $0 \%$ & 2,00 & 1,50 \\
\hline
\end{tabular}

FIG. 3 THE MODIFIED DURATION FOR BOTH TECHNIQUES SHOWS AN INVERSE RELATIONSHIP WITH THE CAPITALIZATION RATE ALTHOUGH WITH DIFFERENT DEGREES

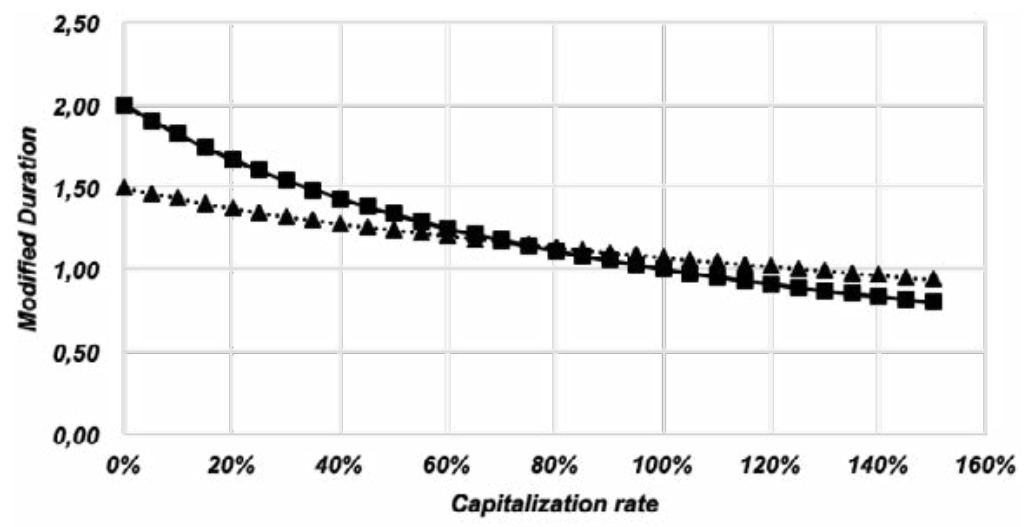

For the modified duration, the classic inverse relationship between interest rate and modified duration holds ${ }^{10}$. The economic

10 The relationship is non-linear as the modified duration changes for different interest rates, something that it is captured by the convexity of the stream (Tuckman and Serrat 2012, p. 130-135). 
interpretation is clear: the lower the interest rate, the more sensitive the present value of a production technique is to changes in the interest rate.

Once we have the different Macaulay and modified durations for each production technique and capitalization rate, it is possible to plot both measures for an economy that would be formed by entrepreneurs choosing between $A$ and $B$. We already know which technique will be selected for each interest rate, as discussed in section 1, so the capitalized present value, the Macaulay duration and the modified duration of that economy corresponds to the chosen technique ${ }^{11}$ :

TABLE 5. CLC, MACAULAY DURATION AND MODIFIED DURATION FOR THE ECONOMY

\begin{tabular}{ccccc}
\hline $\begin{array}{c}\text { Capitalization } \\
\text { rate }\end{array}$ & $\begin{array}{c}\text { Chosen } \\
\text { technique }\end{array}$ & CLC Economy & $\begin{array}{c}\text { Duration } \\
\text { Economy }\end{array}$ & MD Economy \\
\hline $150 \%$ & $A$ & 43,75 & 2,00 & 0,80 \\
\hline $125 \%$ & $A$ & 35,44 & 2,00 & 0,89 \\
\hline $100 \%$ & Indifferent & 28,00 & 2,07 & 1,04 \\
\hline $75 \%$ & $B$ & 21,22 & 2,01 & 1,15 \\
\hline $50 \%$ & Indifferent & 15,75 & 1,93 & 1,29 \\
\hline $25 \%$ & $A$ & 10,94 & 2,00 & 1,60 \\
\hline $0 \%$ & $A$ & 7,00 & 2,00 & 2,00 \\
\hline
\end{tabular}

In terms of capitalized labor costs, there is a positive but not linear relationship between capitalization rate and CLC for the economy:

11 For capitalization rates where agents are indifferent towards both techniques, I will use the average of the duration and modified duration of $A$ and $B$ as they are both equally valuable. 
FIG. 4 CAPITALIZED LABOR COST FOR THE ECONOMY.

CALCULATED AS THE CLC OF THE SELECTED TECHNIQUE

(VERTICAL AXIS) FOR EACH CAPITALIZATION RATE

(HORIZONTAL AXIS). THE UPWARDS SLOPING CURVE REFLECTS

THE INCREASING LABOR COST OF PAST PERIODS AS THE

INTEREST RATE INCREASES

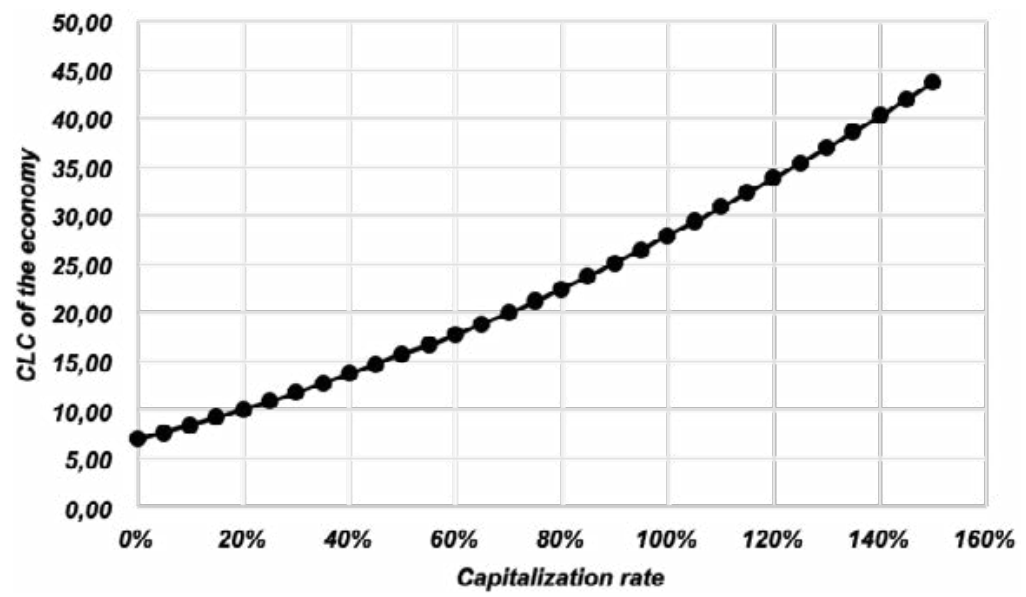

Looking at Macaulay duration, we see in Figure 5 how it both decreases and increases as capitalization rates go higher, the reason being the switch from technique $A$, with has a constant duration of 2, to $B$ which has a lower duration than $A$ at an interest rate of $50 \%$ and a higher one at $100 \%$ when the reswitching takes place. 
FIG. 5 MACAULAY DURATION/HICKS'S APP FOR THE ECONOMY.

CALCULATED AS THE MACAULAY DURATION FOR THE SELECTED TECHNIQUE AND THE AVERAGE OF $A$ AND $B^{\prime} S$ DURATION WHEN THEIR CLC IS THE SAME (AT CAPITALIZATION RATES OF 50\% AND 100\%)

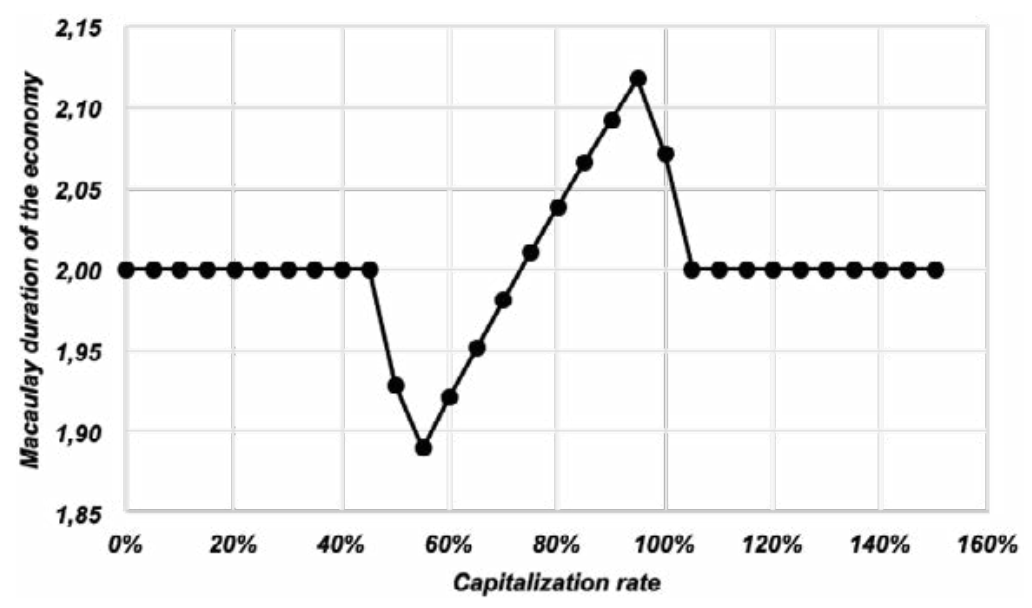

Finally, the picture for modified duration (Figure 6) shows a downward sloping curve with respect to interest rates. In other words, the economy, measured as the present value of the selected technique, becomes more sensitive to changes in interest rates as the latter decrease; i.e. for a $100 \mathrm{bps}$ change in the discount rate, the change in the present value of the economy will be higher the lower the interest rate, even when there is a reswitch between techniques. 
FIG. 6 MODIFIED DURATION FOR THE ECONOMY. CALCULATED AS THE MODIFIED DURATION FOR THE SELECTED TECHNIQUE AND THE AVERAGE OF $A^{\prime}$ 'S AND B'S MODIFIED DURATION WHEN THEIR CLC IS THE SAME (AT DISCOUNT RATES OF 50\% AND 100\%)

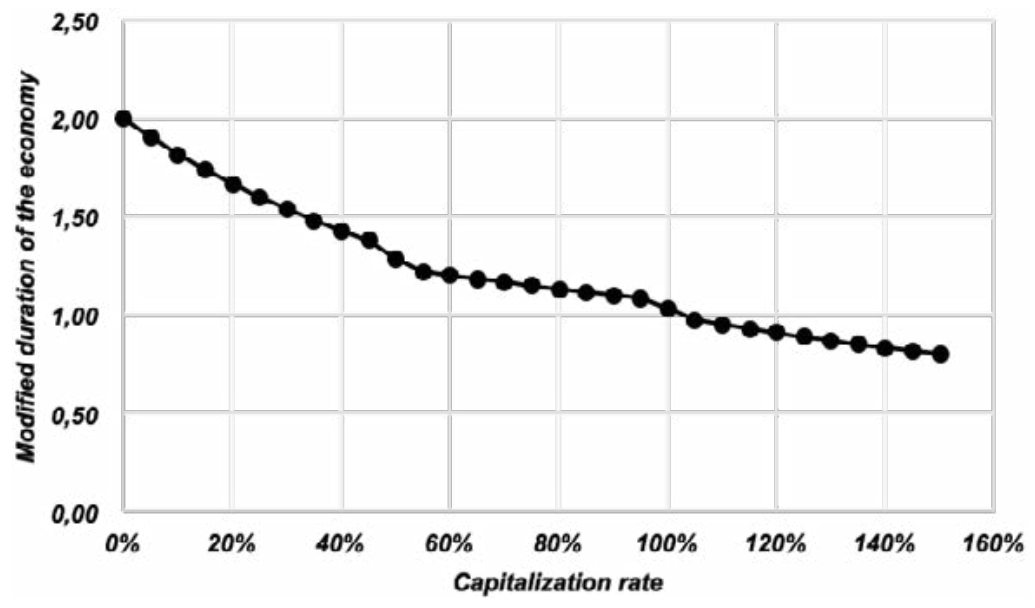

In conclusion, we can see that (1) when applying the Macaulay duration or Hicks's APP as the measure of the 'roundaboutness' of the economy, it first decreases and then increases when the capitalization rate goes from $0 \%$ to $150 \%$, something that contradicts one of the main assumptions of the ACBT, and (2), on the contrary, when using the modified duration: lower interest rates always lead to a more roundabout productive structure and vice versa ${ }^{12}$.

Therefore, the key point is which measure of 'roundaboutness' is more appropriate. The first question is whether the interest rate has to be included. On his original article, Samuelson (1966, p. 582583) already argued against it:

12 This is the case even though the modified duration of A is higher than B's for $r$ $<75 \%$ but lower for $\mathrm{r} \geq 75 \%$ as can be seen in Figure 3. For the 'Austrian' approach, the relevant issue is how the roundaboutness of the productive structure changes in response to a change in interest rates, not the relative roundaboutness of each technique for a particular interest rate. 
"There often turns out to be no unambiguous way of characterizing different processes as more 'capital-intensive', more 'mechanized', more 'roundabout', except in the ex post tautological sense of being adopted at a lower interest rate and involving a higher real wage. Such a tautological labeling is shown, in the case of reswitching, to lead to inconsistent ranking between pairs of unchanged technologies, depending upon which interest rate happens to prevail in the market."

From a financial point of view, from the perspective of entrepreneurs choosing among different production techniques, the interest rate is a key factor as the measure of inter-temporal valuation, required to compare cash flows in different time periods and, therefore, has to be necessarily taken into account. This is the standard practice in corporate finance, where investment projects are ranked according to their Net Present Values (NPV) and such rankings will depend on interest rates, even if they represent 'unchanged technologies'.

Samuelson himself is including the temporal valuation when ranking both production techniques as the chosen one is that with the lowest present value, i.e. cost. It is not coherent using the capitalization rate for the ranking of production processes but not for their 'roundaboutness', as that implies using the value of time on one measure but not in the other ${ }^{13}$. This is precisely why BöhmBawerk's APP has to be discarded, and the phenomenon of reswitching can be interpreted as a successful argument for its dismissal.

As we saw above, Hicks (1953) and Cachanosky and Lewin (2014) have argued that duration should be used as the proper

13 'A satisfactory solution [to the reswitching controversy], in my judgment, requires a theory that (1) takes explicit account of the time dimension in the production process and (2) takes the interest rate as a market-determined allocator of saving among different, temporally defined uses.' (Garrison 2005: 15). This same argument applies against measuring productivity as the output per unit of labor, for different techniques, without taking into account the time dimension as Fratini (2019a and b) does: even though the ratio of output to units of labor is $1 / 7$ for $A$ and $1 / 8$ for $B$ regardless of the prevailing interest rate, that does not mean the productivity of $\mathrm{A}$ is always higher than B's, as we also need to take into account the value of time when comparing inputs used in different periods; that is why we use NPVs as the raking criteria in the first place. 
average period of production; and Osborne and Davidson (2016) have proved that duration is already included in Samuelson's equations in the form of the unorthodox roots ${ }^{14}$. However, we have seen there no inverse relationship between interest rates and roundaboutness when using Macaulay duration, but that that is the case for the modified duration. The question is: is there an economic reason to choose the latter? Or it is just a selection based on an 'ex post tautological sense'? 15

Although closely related, Macaulay duration and modified duration have different interpretations as explained above: the first is the average of the time distance of cash flows, weighted by their discounted/capitalized value; the second, the sensitivity of its present value to changes in the interest rate. In what follows, I will argue that only the modified duration is an appropriate economic measure for the roundaboutness of production techniques, or for a combination of them constituting an economy. This is so for two reasons: (1) Macaulay duration is only relevant for ranking the sensitivity of different cash streams for a particular interest rate, not for measuring the specific changes in net present value of a project with respect to interest rates and, because of that, (2) Macaulay duration cannot be used to compare the same or different techniques for different interest rates and, therefore, a combination of them. Modified duration, on the contrary, fulfills both requirements:

14 Osborne and Davidson (2016) have presented a new approach to the reswitching problem by including the unorthodox roots in the analysis. The equations used on the reswitching controversy are polynomials of degree $n$ which have $n$ roots (with $n=3$ on the Samuelson example) of the form $1+r$. Therefore, for each value of the equation (for each capitalized labor cost) there are three solutions of the form $1+r$, with $\mathrm{r}$ being an interest rate. However, two of those roots are 'unorthodox' as they are negative, real or complex numbers and are usually discarded in the financial analysis (Boulding 1936, p. 440). They prove that (1) when adding the unorthodox roots in the analysis, there can be switching but not reswitching and (2) the product of the unorthodox roots "is a summary statistic -duration (Macaulay 1938)- describing the present-value weighted-average timing of the labor inputs (after a small prior adjustment)" (Osborne and Davidson 2016, p. 9).

15 More recently, Vienneau (2017) has also argued that the multiple interest rate analysis of reswitching, carried out by Osborne and Davidson (2016), is based on a tautology. Another reason why it is necessary to demand an economic interpretation for the modified duration as a measure of roundaboutness. 
(1) Relationship with Net Present Value. Although the Macaulay duration can be used to compare the sensitivity of different streams to changes in the interest rate, it does not provide information about the specific change in the net present value of a cash stream for different interest rates. This can be clearly seen in Samuelson's example: $A$ has a constant Macaulay duration of 2 regardless of the prevailing capitalization rate, behaving like a two-year zero coupon bond. However, the change of its NPV is not the same for every capitalization rate: when the interest rate goes from $149 \%$ to $150 \%$ the $A^{\prime}$ 's NPV changes from 43,40 to 43,75 , an increase of $0.80 \%$. For an equivalent increase of $100 \mathrm{bps}$, but starting at an interest rate of $0 \%$, the NPV increases from 7,00 to 7,14 $(+2 \%)^{16}$. The percentage changes coincide with A's modified duration at each capitalization rate $^{17}$.

Although $A$ is an extreme example, being equivalent to a zero coupon bond, it also shows that the Macaulay duration of a fixed coupon bond, i.e. with intermediate payments, will not be a good indicator either for changes in its NPV with respect to changes in the discount rate. Therefore, Hicks's APP is not a good measure in order to understand the relationship between the NPV, the ranking method, and the interest rate; modified duration is.

(2) One or more techniques cannot be compared, for different interest rates, by using their Macaulay duration. Following the above, having a project with a higher or lower Macaulay duration than another does not provide information on their specific behavior, only their ranking in terms of sensitivity with respect to changes in the interest rate, which is the key question for the phenomenon of the reswitching of techniques. The higher the interest rate, assuming a lower bound at $0 \%$, the bigger the difference between both measures and, therefore, the more misleading their comparison would be.

For this same reason, calculating the Macaulay duration of an economy, obtained as the Macaulay durations for the selected projects for each interest rate, does not provide a reliable measure of the relationship between the present value of their combined cash flows and changes in the interest rate. This can easily be seen comparing Figure 4 and Figure 5 when the capitalization rate is

16 This is the reason why the relationship between CLC and capitalization rate is positive but not linear.

17 The percentage change will also coincide with Macaulay duration when the interest rate is $0 \%$ as both measures will be the same. 
reduced from $95 \%$ to $55 \%$ : while the Macaulay duration for the economy decreases, the modified duration increases, correctly signaling a higher sensitivity to changes in the interest rates.

For these reasons, modified duration should be used as the measure for roundaboutness for a particular technique or for a combination of some of them. Thus, we can conclude that, for Samuelson's model or any other generated in the same way (Garrison 2005), the productive structure of an economy will become more sensitive (roundabout) the lower the interest rate, even when there is a reswitching of productive techniques. This implies that the phenomenon of reswitching does not contradict the $\mathrm{ABCT}$ as it is logically possible to have a reswitching between techniques while, at the same time, maintaining the inverse relationship between interest rates and roundaboutness, if the financial approach is consistently applied.

\section{Reswitching with fully flexible prices}

So far, the analysis has been focused on comparative statics, i.e. on the study of which production technique will be selected by entrepreneurs for each capitalization rates, assuming fixed monetary costs and revenues. This is where Hicks (1953) developed his study and where the use of the modified duration becomes relevant as a measure of roundaboutness. However, in his original article, Samuelson (1966, p. 571) provided another critique of Hicks's APP from a different perspective:

\footnotetext{
"Actually, however, the Value and Capital definition cannot even be applied to the comparisons of Ia, Ib, Ic or IIa, IIb. For Hicks's definition must take into account the fact that, under perfect competition with free entry and constant returns to scale, the prices of all final, intermediate, and input goods will change with the interest rate until net present-discounted values are again zero. Then his average is found to be always infinite!"
}

With fully flexible prices and fixed revenues, the net present value of any technique will be zero by definition as entrepreneurs 
will bid up the inputs until they reach a price in which the profitability of the investment project, its internal rate of return, is equal to the interest rate. For an NPV of 0 both the Macaulay duration and modified duration will be undefined. But that is not the only consequence of shifting the analysis towards this approach: the NPV of all techniques will have to be 0 for each interest rate; this implies that the price of a unit of labor will have to change differently for each technique.

We have been assuming that each labor unit has a cost of 1 during the comparative statics' analysis. This was a useful assumption in order to understand how entrepreneurs will choose between different techniques for which they face fixed costs. However, if we move to world with flexible prices, the price of each labor unit will have to diverge if entrepreneurs are to be indifferent among each productive technique for a specific interest rate: in equilibrium, the discounted/capitalized price of the labor units employed for each technique must be equal to the discounted/capitalized price of one unit of output; and since the number and temporal distribution of labor units employed are fixed, their price will have to change for each interest rate. By definition, since the temporal distribution and number of labor units are different for each productive technique, their prices will have to move in different ways.

Let us return to Samuelson example and calculate for each technique the nominal unitary price for a unit of labor in equilibrium; that is, the unitary nominal wage that would make entrepreneurs indifferent in choosing among techniques assuming flexible input prices.

Starting with $A$ (Table 6), we see that as long as it is the technique with the lowest CLC, and when $A$ and $B$ have the same present cost, the price for a unit of labor remains at 1 . However, in the equilibrium for an interest rate of $75 \%$, an entrepreneur would only be able to bid up to 0,99 monetary units for a labor unit in order be indifferent between $A$ and $B$. In other words, the nominal labor cost of a unit used by $A$ should fall by $1 \%$ in order to show the same CLC as $B$. 
TABLE 6. EQUILIBRIUM NOMINAL WAGE FOR $A$

\begin{tabular}{cc}
\hline Interest rate & Nominal unitary wage in equilibrium for technique $A$ \\
\hline $150 \%$ & 1,00 \\
\hline $125 \%$ & 1,00 \\
\hline $100 \%$ & 1,00 \\
\hline $75 \%$ & 0,99 \\
\hline $50 \%$ & 1,00 \\
\hline $25 \%$ & 1,00 \\
\hline $0 \%$ & 1,00 \\
\hline
\end{tabular}

Applying the same reasoning to $B$, for each interest rate, we get an undetermined system of equations as we have two unknowns, the future value of one unit of labor at $t=3$ and the one at $t=1$, but only one equation of the form:

$$
C L C_{\mathrm{eq}}=2 w_{1} \cdot(1+r)^{3}+6 \omega_{3} \cdot(1+r)
$$

Where $C L C_{e q}$ is the capitalized labor cost of the most profitable technique for the interest rate $r, w_{1}$ the nominal value of a unit of labor employed in $\mathrm{t}=1$, and $w_{3}$ the nominal value of a unit of labor employed in $t=3$. The last two variables are unknowns thus making the system undetermined. In Samuelson example, it is implicitly assumed that the nominal unitary wages are equal for all stages and techniques, so we can assume that $w_{1}$ and $w_{3}$ are equal: 
TABLE 7. EQUILIBRIUM NOMINAL WAGE FOR B ASSUMING EQUAL UNITARY WAGES

\begin{tabular}{cc}
\hline Interest rate & Nominal unitary wage in equilibrium for technique $\boldsymbol{B}$ \\
\hline $150 \%$ & 0,95 \\
\hline $125 \%$ & 0,98 \\
\hline $100 \%$ & 1,00 \\
\hline $75 \%$ & 1,00 \\
\hline $50 \%$ & 1,00 \\
\hline $25 \%$ & 0,96 \\
\hline $0 \%$ & 0,88 \\
\hline
\end{tabular}

For an interest rate of $150 \%$, a nominal unitary wage of 0,95 monetary units makes the present value of all labor employed equal to that of technique $A$, which is the selected one. Only when $B$ is selected, the unitary wage is 1 .

Comparing Table 6 and Table 7, we can see that equilibrium requires different unitary wages for the labor employed by $A$ and $B$ except when both are equivalent in terms of present value, i.e. at an interest rate of $50 \%$ and $100 \%$.

Thus, it is true that assuming a situation of flexible prices makes the modified duration meaningless but that comes at a price: the price of labor becomes fully flexible and has to adapt to the interest rate, it cannot be fixed and uniform as in Samuelson example (Rallo 2010). And the flexibility of labor prices implies that any productive technique whatsoever; any possible combination of labor inputs, be it $A, B$ or any other, will also have the same present cost as the price for its labor inputs will be adjusted automatically to the value of the output, making their NPV equal to 0: all techniques will have the same capitalized cost and entrepreneurs will be indifferent in choosing among all of them.

Therefore, in equilibrium with flexible prices, there is no difference between techniques, and this is the reason why modified duration becomes meaningless: the NPV is completely fixed at 0 and no change in the interest rate will affect it, as the full 
adjustment is automatically borne by the labor price in a non-uniform way. The objective of any measure of roundaboutness, in the context of the $\mathrm{ABCT}$, is to analyze different productive structures when there is a change in the interest rate but, in equilibrium, there are no differences at all in terms of NPV; all techniques are, by definition, equivalent for any interest rate ${ }^{18}$.

\section{The dynamic efficiency approach}

So far we have analyzed the phenomenon of reswitching from the perspective of comparative statics and flexible prices, I will end with the Austrian dynamic efficiency approach whose focus is the entrepreneurial activity which is continuously discovering and creating new sets of ends and means (Huerta de Soto 2010).

It is possible to adapt this approach with a simple case, similar to the ones previously employed. Let us start with one particular output that it is expected to have a particular monetary value in a specific time period in the future; once the expectations are set up, entrepreneurs will try to find the techniques that provide a positive NPV given their cost of capital, with the ones with higher NPVs being selected first. A technique is characterized as a mix of labor units in different time periods and available at different prices. The number and composition of techniques is not fixed, as in Samuelson example, but open to changes and new additions following the creative nature of entrepreneurship. However, this creativity will not be a random appearance of new techniques but will be guided by their resulting NPVs. For a given expected price for the output and interest rate, only the new techniques with positive net present values will be adopted, and the ones with the higher NPV will be selected first.

Let us assume now that only the expected price of the output is fixed but not the interest rate. In this situation, the NPV of all available techniques, and therefore their selection, will depend on the

18 In a sense, when all NPVs are 0 and all modified durations are undefined, is when there is no entrepreneurship activity, i.e. when there is place for no human action. 
prevailing interest rate. New techniques, or previously discarded ones, will only be adopted if their NPV, at the new interest rate, is positive, and the ranking of techniques according to their NPV will change too. Higher interest rates will incentivize the deferral of nominal payments ceteris paribus, benefiting the NPV of those techniques that require disbursements for inputs at more distant periods of time, i.e. less capitalized; and lower interest rates will favor the anticipation of nominal payments ${ }^{19}$.

Those techniques with more sensitivity to changes in interest rates, i.e. with a higher modified duration, will see how their NPVs change proportionally more, increasing (decreasing) more when interest rates decrease (increase), and moving higher (lower) on the raking of all projects available, as stated by the ABCT. Thus, there will be a tendency towards a different time distribution of the cash flows, for the selected techniques, as the economy moves towards the new equilibrium after a change in interest rates.

However, the equilibrium will never be reached as (1) the expected price for an output will be based upon both entrepreneurs' expectations and consumers' valuations, which are not fixed but subject to continuous changes and (2) the range of possible techniques is not fixed either but open to new formulas and additions. Thus, the lower the NPV of a technique, even before it reaches 0 , the more likely it will be its replacement by new combination of inputs and factor prices.

\section{Conclusion}

The phenomenon of reswitching is a relevant critique of the link, established by the traditional $\mathrm{ABCT}$, between interest rates and the roundaboutness of an economy, understood as a measure of the distance in time between inputs and outputs. Its importance cannot be downplayed by the fact of the high interest rates used by

19 For more complex cash flow streams, another possible approach is, following Sargan (1955), to calculate separately the revenue and the cost streams: higher interest rates will incentivize the deferral of nominal payments and the earlier receipt of revenues, and vice versa. 
Samuelson (1966) in his example; as Garrison (2005) has showed, it is easy to obtain the same reswitching for more realistic levels. In this sense, Sraffians are right: reswitching proves that no physical measurement of roundaboutness exists.

I have tried to show, however, that this does not imply there is no relationship between the interest rate and the productive structure, if the Austrian subjective perspective is consistently applied. Following Hicks (1953) and Cachanosky and Lewin (2014), it can be shown that using the financial approach leads to an economic solution of Samuelson's paradox, by focusing on the sensitivity to interest rates of the different productive techniques. This is the reason why both Böhm-Bawerk's APP and Macaulay duration/Hicks's APP are not appropriate measures of roundaboutness, but modified duration is, as the latter provides a quantitative measure of changes in the net present value of a cash flow stream with respect to changes in the interest rate. Therefore, and according to the classic relationship of fixed income, the lower (higher) the interest rate, the higher (lower) the sensitivity of the present value of a particular productive technique, or a combination of them that conforms an economy, even in those cases when there is a reswitching of techniques.

If the above is correct, the traditional relationship in the Austrian tradition between interest rates and roundaboutness holds, even when the phenomenon of reswitching takes place, and can help to explain how the productive structure is modified along the monetary cycle and expand the dynamic efficiency approach.

\section{REFERENCES}

Böhm-Bawerk, E. V. (1884). The Positive Theory of Capital. New York: G. E. Stechert \& Co. [1891]

Boulding, K. (1936). 'Time and Investment: A Reply.' Economica 3 (12): 440-442. https://doi.org/10.2307/2549249.

Cachanosky, N., \& Lewin, P. (2014). 'Roundaboutness is not a Mysterious Concept: A Financial Application to Capital Theory.' Review of Political Economy 26 (4): 648-665. doi:10.1080/09538259. 2014.957475. 
Cohen, A. J. (2010). 'Capital Controversy From Bhohm-Bawerk to Bliss: Badly Posed or Very Deep Questions? Or What "We" Can Learn From Capital Controversy Even If You Don't Care Who Won.' Journal of the History of Economic Thought 32 (1): 1-21. https://doi.org/10.1017/S105383720999040X

Fratini, S. M. (2019a). 'A note on re-switching and the neo-Austrian concept of the average period of production.' The Review of Austrian Economics. https://doi.org/10.1007/s11138-019-0432-0

- (2019b). 'Re-switching and the Austrian business-cycle theory: A rejoinder' The Review of Austrian Economics. https://doi. org/10.1007/s11138-019-00467-8

Garrison, R. W. (2005). 'Reflections on Reswitching and roundaboutness'. Money and Markets: Essays in Honor of Leland B. Yeager. London: Routledge. https://doi.org/10.4324/9780203799246.

Hayek, F. A. (2008). Prices and Productions and Other Works. Auburn, AL: Ludwig von Mises Institute.

Hicks, J. R. (1953). Value and Capital. London: Oxford University Press.

Huerta de Soto, J. (2010). The Theory of Dynamic Efficiency. London: Routledge.

Lewin, P., \& Cachanosky, N. (2019). 'Re-switching, the average period of production and the Austrian business-cycle theory: A comment on Fratini.' The Review of Austrian Economics. https:// doi.org/10.1007/s11138-019-00460-1

Macaulay, F. R. (1938). Some Theoretical Problems Suggested by the Movement of Interest Rates, Bond Yields, and Stock Prices in the US Since 1856. New York: National Bureau of Economic Research.

Mises, L. V. (1921). The Theory of Money and Credit. New Haven: Yale University Press [1953].

Rallo, J. R. (2010). 'El Mito del Reswitching.' https://www.juandemariana.org/ijm-actualidad/analisis-diario/el-mito-del-reswitching. Accessed 23 January 2019.

Osborne, M., \& Davidson, I. (2016). 'The Cambridge capital controversies: contributions from the complex plane.' Review of Political Economy 28 (2): 251-269. https://doi.org/10.1080/09538259.201 5.1129751

Samuelson, P. (1966). 'A Summing up.' Quarterly Journal of Economics 80 (4): 568-583. doi:10.2307/1882916. 
Sargan, J. D. (1955). 'The Period of Production.' Econometrica 23

(2): 151-165. https://doi.org/0012-9682(195504)23:2<151:TPOP> 2.0.CO;2-5

Sraffa, P. (1960). Production of Commodities by Means of Commodities:

Prelude to a Critique of Economic Theory. Cambridge: Cambridge University Press.

Tuckman, B., \& Serrat, A. (2012). Fixed Income Securities. New Jersey: Wiley Finance.

Vienneau, R. L. (2017). 'The Choice of Technique with Multiple and Complex Interest Rates.' Review of Political Economy 29 (3): 440 453. https://doi.org/10.1080/09538259.2017.1346039 